\title{
ATUAÇÃO DE DOCENTES DO GÊNERO MASCULINO NA EDUCAÇÃO ESPECIAL SUL-MATO-GROSSENSE ${ }^{1}$
}

\section{PERFORMANCE OF MALE TEACHERS IN SPECIAL EDUCATION IN SOUTH-MATO- GROSSENSE}

\author{
Matheus Kashiyama Pessoa ${ }^{2}$ \\ Josiane Peres Gonçalves ${ }^{3}$
}

\begin{abstract}
RESUMO: A temática da pesquisa refere-se ao trabalho educativo exercido por professores homens que atuam na Educação Especial com alunos que possuem deficiências e teve o objetivo de identificar as percepções de docentes, familiares e gestores da área de educação especial sulmato-grossense, em relação ao trabalho educativo desenvolvido por docentes do gênero masculino. A metodologia utilizada se caracteriza por uma pesquisa qualitativa do tipo descritiva e a coleta de dados foi realizada a partir de um roteiro semiestruturado, que foi utilizado para a gravação de entrevistas individualizadas. Devido ao contexto de pandemia e adoção do isolamento social como medida de proteção ao Covid-19, a pesquisa de campo foi realizada com o uso do aparelho celular e do aplicativo Whatsaap. Participaram da pesquisa: uma gestora da APAE, um professor homem que atua na mesma APAE e uma mãe de uma menina que estudava com um professor homem em outra APAE de Mato Grosso do Sul. Os resultados do estudo evidenciam que as famílias de alunos com deficiência tendem a pensar o cuidar acima do educar. Assim, há um certo estranhamento ao ver um professor homem atuando com crianças especiais, apontando para o grande temor das mães em relação ao abuso sexual e a pedofilia, acabando por restringir o professor homem de exercer atividades voltadas ao cuidado pessoal e práticas higienistas. Percebe-se que há uma certa dificuldade dos pais e da instituição APAE de olhar o professor homem como um profissional da educação.
\end{abstract}

Palavras-chaves: Gênero. Docência Masculina. Educação Especial. Professores Homens.
ABSTRACT: The research theme refers to the educational work carried out by male teachers who work in Special Education with students who have disabilities and aimed to identify the perceptions of teachers, family members and managers in the special education area of Mato Grosso, in relation to the educational work developed by male teachers. The methodology used is characterized by a qualitative research of the descriptive type and the data collection was carried out from a semi- structured script, which was used to record individualized interviews. Due to the context of the

\footnotetext{
${ }^{1}$ A pesquisa foi financiada pelo CNPq e UFMS.

${ }^{2}$ Graduando em Pedagogia pela Universidade Federal de Mato Grosso do Sul. Bolsista de Iniciação Científica PIBIC/UFMS. E-mail: matheuskashiyama@live.com

${ }^{3}$ Doutora com Pós-Doutorado em Educação pela Pontifícia Universidade Católica do Rio Grande do Sul (PUCRS). Professora do Programa de Pós-graduação em Educação da Universidade Federal de Mato Grosso do Sul. Líder do Grupo de Estudo e Pesquisa em Desenvolvimento, Gênero e Educação (GEPDGE). E-mail: josiane.peres@ufms.br Cadernos Cajuína, v.5, n.3, Setembro-2020 
pandemic and the adoption of social isolation as a protection measure for Covid-19, the field research was carried out using the cell phone and the Whatsaap application. Participated in the research: an APAE manager, a male teacher who works at the same APAE and a mother of a girl who studied with a male teacher at another APAE in Mato Grosso do Sul. The results of the study show that the families of students with disabilities they tend to think of caring over educating. Thus, there is a certain strangeness when seeing a male teacher acting with special children, pointing to the mothers' great fear in relation to sexual abuse and pedophilia, ending up restricting the male teacher from exercising activities aimed at personal care and hygienist practices. It is noticed that there is a certain difficulty for parents and the APAE institution to look at the male teacher as an education professional.

Key-words: Genre. Male Teaching. Special education. Male Teachers.

\section{INTRODUÇÃO}

O presente trabalho encontra-se vinculado à pesquisa "Atuação de Docentes do Gênero Masculino na Educação Especial Sul-Mato-Grossense", financiada pelo CPNq, realizada no Paraguai e alguns municípios sul-mato-grossenses. Para este estudo, especificamente, foi priorizado a seleção de um município que tinha homens atuando como docente na área de educação especial, cujo atendimento era exclusivamente com alunos que tinham algum tipo de deficiência, tendo isso em vista a pesquisa foi realizada com pessoas vinculadas a duas Associação de Pais e Amigos dos Excepcionais (APAE) de dois municípios de Mato Grosso do Sul.

O estudo se justifica como relevante porque atualmente as relações de gênero nas instituições escolares, principalmente no que diz respeito à docência masculina na Educação Especial, tem sido pouco pesquisada e discutida no meio acadêmico, levando em consideração que muitos pesquisadores como Gonçalves, Faria (2015), Gonçalves, Dias, Souza (2017), Gonçalves, Ferreira e Capristo (2018) tem realizado pesquisas voltadas para as representações sociais conferidas aos docentes masculinos que lecionam na Educação Infantil e Ensino Fundamental com crianças sem deficiências.

Deste modo, por se tratar de um tema que tem priorizado questões inerentes ao gênero masculino em pesquisas de Educação Infantil e Ensino Fundamental em escolas de ensino comum, quando voltamos o olhar para a Educação Especial, percebemos que ainda permanece como um problema sem resposta, visto que não foram encontradas revisões de literatura que abordassem sobre a atuação de docentes do gênero masculino com alunos com deficiência.

Diante desta escassez de investigação no meio acadêmico, surge a necessidade de realizar um estudo sobre o trabalho desenvolvido por docentes do gênero masculino na área da Educação Especial em municípios do Estado de Mato Grosso do Sul que tenham homens atuando como 
professores nessa modalidade de ensino. A intenção é compreender as percepções da comunidade escolar, entendida como gestores, docentes e familiares, de uma Associação de Pais e Mestres do Excepcionais (APAE) sul-mato-grossense, sobre o trabalho de professores homens com alunos de educação especial, ou seja, alunos que tenham algum tipo de deficiência.

É importante considerar que, devido à dificuldade de encontrar produções acadêmicas que abordassem a atuação de professores homens na área de educação especial, procuramos embasamento teórico a partir do conhecimento disponibilizados pelas pesquisas voltadas a Educação Infantil e Ensino Fundamental em escolas de ensino comum, para fundamentar o presente trabalho, mas sempre procurando relacionar esses conhecimentos com a área de educação especial.

Ao realizar um estudo sobre atuação de docentes do gênero masculino com crianças, no estado de Mato Grosso do Sul, pesquisadoras como Gonçalves e Faria (2015), Gonçalves, Ferreira e Capristo (2018) ressaltam que, na Educação Infantil, o docente do gênero masculino sofre preconceitos referentes as práticas pedagógicas relacionadas a higiene e ao cuidado das crianças pequenas, sendo então os homens professores excluídos de tal função, tendo em vista que em todas instituições que serviram como objeto de estudo para coleta de dados, apenas professoras ou auxiliares do sexo feminino poderiam realizar tais práticas. Tal prática ocorre porque gestores e docentes têm receio sobre o que os familiares vão pensar de ter homens trocando fraudas e dando banhos em crianças pequenas nas instituições de educação infantil, restando a eles ficarem somente com as "atividades pedagógicas", como se as práticas higienista e de cuidado não fossem importantes no trabalho desenvolvido por docentes do gênero masculino.

Já nos anos iniciais do Ensino Fundamental, as pesquisas de Gonçalves, Dias, Souza (2017) retratam um cenário repleto de preconceitos e estereótipos acerca do docente masculino, sendo percebido o predomínio de representações de que, por ser homem, o profissional tende a ser visto como rude, grosseiro, autoritário e agressivo, além de serem considerados incapazes para lidar com crianças que necessitam de carinho, amor, cuidado e paciência, habilidades que apenas uma mulher saberia desempenhar, devido a sua "natureza" maternal. Outro fator apontado, e que gera grande receio, é a questão do contato físico do professor homem com alunas, que está relacionado ao ato de pedofilia, dando a entender que todo homem é um potencial estuprador, que não consegue exercer controle por sua sexualidade, criando novamente uma contradição entorno das mulheres, como se esta fosse apta a lecionar nesse nível de ensino, por ser dotada de uma sexualidade passiva e maternal, o que acaba isentando as professoras de um possível vínculo com a pedofilia, como se nenhuma mulher fosse capaz de realizar tal ato. 
De acordo com Ramos (2011), ao iniciar a carreira profissional ou ir para uma nova instituição de ensino, os docentes masculinos tendem a passar por um "período comprobatório", no qual se estende para além do período probatório, servindo como um tempo em que os professores homens devem comprovarem e convencerem a comunidade escolar que estão aptos, que são capazes e que possuem conhecimentos, competências e habilidades para exercerem sua profissão de forma profissional e ética, em relação a questões referentes a educação e o cuidado das crianças pequenas.

Cabe salientar que o período comprobatório, atribuído pela instituição, não se caracteriza por um tempo predefinido, uma vez que "esse período se estabelece em função das características do próprio espaço de atuação e de seus diferentes sujeitos" (RAMOS, 2011, p. 31), servindo como um momento de prova de suas capacidades no exercício da docência, para então ser reconhecido e "legitimado" como professor pela instituição.

De fronte a este panorama, percebe-se o grande impacto que questões relacionadas ao gênero exercem na profissão de professores homens, que realizam docência em instituições voltadas a Educação Infantil e Ensino Fundamental, em áreas consideradas como femininas pela sociedade. Dessa forma, o conceito de gênero não abrange apenas a diferenciação dos sexos entre masculino e feminino e, diante disso, é interessante pensar como o gênero gera impacto no âmbito social, definindo padrões estereotipados já preestabelecidos pela sociedade, dos quais são atribuídos como ações próprias do homem e da mulher, no qual os mesmos se acostumam a exercê-los e os naturalizam, devido aos hábitos adquiridos tanto social quanto culturalmente e historicamente (GUEDES, 1995; HIRATA; KERGOAT, 2007).

Diante deste cenário, Bourdieu (2012, p. 18) relata que "o mundo social constrói o corpo como realidade sexuada e como depositário de princípios de visão e de divisão sexualizantes", ou seja, a sociedade impõe as pessoas modelos a serem seguidos, de acordo com a diferença biológica, e então categorizam, condicionam e naturalizam as ações ou atividades humanas, determinando as funções que são vistas como próprias para os homens e próprias para as mulheres. Nesse sentido, perpetua-se a dominação e subordinação que a sociedade impõe do homem em relação à mulher, e reforça o discurso "naturalizado" para diferenciar as posições de poder socialmente construídas sobre gênero. E quando se trata da divisão de trabalho, percebe-se que existem algumas características atribuídas à "designação prioritária dos homens à esfera produtiva e das mulheres à esfera reprodutiva e, simultaneamente, a apropriação pelos homens das funções com maior valor social adicionado" (HIRATA; KERGOAT, 2007, p. 599).

A divisão sexual do trabalho se faz presente em diversos contextos da sociedade e, consequentemente, em âmbito escolar, sendo então oportuno compreender que: 
Essa forma particular da divisão social do trabalho tem dois princípios organizadores: o princípio de separação (existem trabalhos de homens e trabalhos de mulheres) e o princípio hierárquico (um trabalho de homem "vale" mais que um trabalho de mulher). Esses princípios são válidos para todas as sociedades conhecidas, no tempo e no espaço. Podem ser aplicados mediante um processo específico de legitimação, a ideologia naturalista. Esta rebaixa o gênero ao sexo biológico, reduz as práticas sociais a "papéis sociais" sexuados que remetem ao destino natural da espécie. (HIRATA; KERGOAT, 2007, p. 599)

A partir desta perspectiva, é notável que a docência com crianças atualmente é considerada uma área de trabalho feminina perante a sociedade, tendo em vista que tudo que é voltado para a esfera reprodutiva, doméstica, que exige cuidado está associado ao universo feminino e, portanto, as mulheres seriam aptas a atuar com crianças devido a sua "natureza maternal". Entretanto, ressalta-se que a divisão de trabalho é construída socialmente, mas costuma ser entendida como se fossem algo natural, sem perceber que a sociedade exerce uma certa forma de dominação sobre as pessoas desde o seu nascimento, como por exemplo, a compreensão de que "azul é para meninos e rosa para meninas”. Fato semelhante ocorre com as profissões, especialmente em um processo de sexualização do trabalho, em que as pessoas são condicionadas a agir, pensar e trabalhar seguindo os padrões sociais estabelecidos pela sociedade, atribuindo estereótipos para definir o que é voltado para o universo masculino e feminino, de modo que tudo aquilo que fuja da "normalidade" é considerado como estranho ou tanto o homem quanto a mulher tem sua orientação sexual questionada (BOURDIEU, 2012; HIRATA; KERGOAT, 2007; SAYÃO, 2005).

De acordo com Sayão (2005, p. 45-46), a desigualdade se torna evidente "em função de que as atividades femininas possuem menor poder e prestígio em relação às masculinas, independentemente dessas funções serem exercidas por homens ou mulheres”, pois segundo Bourdieu (2012), existe uma dominação masculina que impõe a superioridade masculina em detrimento do que é feminino. Ou seja, mesmo que um homem exerça uma atividade considerada feminina, este estará em condição de menor poder, devido a tal prática ser supostamente “destinada a mulheres", além de colocar as mulheres em posição inferioridade, se levarmos em consideração a relevância social das profissões destinadas ao "público masculino", de acordo com os padrões impostos pela sociedade. Isso ocorre devido as práticas sexistas implícitas nas profissões.

Portanto, a presença masculina se faz importante em áreas consideradas femininas, assim como a presença feminina são importantes em áreas de trabalho consideradas masculinas, porque pode contribuir para desmistificar tabus e paradigmas relacionados as questões de gênero e práticas sexistas no campo profissional. Sendo assim, quanto mais pessoas ingressarem em profissões opostas as que já se apresentam preestabelecidas para determinado gênero, acarretaria em uma 
maior possibilidade de mais pessoas se identificarem e sentirem mais segurança de seguir na carreira, além de reduzir os pensamentos de que determinada profissão é para homem ou para mulher, modificando a perspectivas estereotipadas e sexualizadas que as pessoas apresentam sobre as profissões (HIRATA; KERGOAT, 2007; SAYÃO, 2005).

Perante isso, surge a necessidade de compreender as relações de gênero no âmbito escolar, estabelecidas em torno de professores homens que lecionam com crianças, mais precisamente na área da Educação Especial, tendo em vista que existem publicações voltadas para outras etapas da educação básica, como Educação Infantil e o Ensino Fundamental, mas não foram encontradas pesquisas sobre atuação docente com alunos que tenham algum tipo de deficiência. Além do mais, se na educação infantil um dos problemas é a questão do cuidar ou do contato com o corpo da criança, na Educação Especial também pode ocorrer esse contato mais próximo, visto que, dependendo da deficiência dos alunos, há uma maior necessidade de auxiliá-lo nas questões de higiene, por exemplo. E se na educação infantil existe o receio sobre o que a família vai pensar, cabe refletir se no caso de pessoas com deficiência, que também precisam de cuidados e contatos físicos, se há o receio em ter um docente do gênero masculino desenvolvendo essas atividades em APAEs sul-mato-grossenses.

Devido às limitações auditivas, visuais, cognitivas, físicas, entre outros transtornos globais e funcionais do desenvolvimento que a pessoa com deficiência vivencia, torna-se necessário, para alguns, haver uma atenção maior para suas necessidades educacionais especiais. Essas necessidades, vão desde o simples cuidado para promover a acessibilidade e equidade no ensino, até a realização de práticas higienistas para os que possuem mobilidade limitada, evidenciando assim a predominância do binômio cuidar e educar nas instituições que atendem alunos com deficiência.

De acordo com o documento emitido pelo Ministério da Educação (BRASIL, 2001, p. 56), referente a educação especial, o sistema educacional deve promover a "identificação das necessidades educacionais especiais e a estimulação do desenvolvimento integral do aluno, bem como a intervenção para atenuar possibilidades de atraso no desenvolvimento, decorrentes ou não de fatores genéticos, orgânicos e/ou ambientais". Tais iniciativas são necessárias para contribuir com o bem estar da criança e estão amparadas pelo seguinte Artigo da Lei nº. 7.853:

Art. $2^{\circ}$ Ao Poder Público e seus órgãos cabe assegurar às pessoas portadoras de deficiência o pleno exercício de seus direitos básicos, inclusive dos direitos à educação, à saúde, ao trabalho, ao lazer, à previdência social, ao amparo à infância e à maternidade, e de outros que, decorrentes da Constituição e das leis, propiciem seu bem-estar pessoal, social e econômico. (BRASIL, 1989).

A partir do que foi exposto, sobre a divisão sexual do trabalho e dos preconceitos vivenciados por professores homens que trabalham com criança, destaca-se que o presente estudo 
teve por objetivo identificar as percepções de docentes, familiares e gestores da área de educação especial sul-mato-grossense, em relação ao trabalho educativo desenvolvido por docentes do gênero masculino.

\section{METODOLOGIA}

Em se tratando dos procedimentos metodológicos para a realização desta pesquisa, foi adotado para sua escrita um levantamento bibliográfico em artigos, teses, dissertações, livros e documentos que discutem as relações de gênero nas instituições escolares, mais especificamente sobre a docência masculina, tendo em vista que a "pesquisa bibliográfica também é indispensável nos estudos históricos. Em muitas situações, não há outra maneira de conhecer os fatos passados senão com base em dados secundários” (GIL, 2008, p. 50). Também foi realizada uma pesquisa de campo, para melhor compreender as representações que a comunidade escolar e local atribuem aos professores homens que lecionam na Educação Especial da APAE em dois municípios de Mato Grosso do Sul.

A pesquisa se caracteriza como qualitativa, partindo de uma abordagem descritivo-analítica, pois segundo Creswel (2007), a pesquisa qualitativa considera o sujeito ou objeto de pesquisa como um todo, no qual interpretamos e analisamos todos os aspectos e particularidades, possibilitando assim a análise dos sentimentos, das percepções, das intenções e comportamentos do sujeito de pesquisa. Nesse contexto, “o pesquisador tenta estabelecer o significado de um fenômeno a partir do ponto de vista dos participantes. Isso implica identificar um grupo que compartilha cultura e estudar como ele desenvolveu padrões compartilhados de comportamento com o passar do tempo" (CRESWEL, 2007, p. 37). O autor descreve a pesquisa qualitativa como:

[...] aquela em que o investigador sempre faz alegações de conhecimento com base principalmente ou em perspectivas construtivistas (ou seja, significados múltiplos das experiências individuais, significados social e historicamente construídos, com o objetivo de desenvolver uma teoria ou um padrão) ou em perspectivas reivindicatórias/participatórias (ou seja, políticas, orientadas para a questão ou colaborativas, orientadas para a mudança) ou em ambas. Ela também usa estratégias de investigação como narrativas, fenomenologias, etnografias, estudos baseados em teoria ou estudos de teoria embasada na realidade. O pesquisador coleta dados emergentes abertos com o objetivo principal de desenvolver temas a partir dos dados (CRESWEL, 2007, p. 37).

De acordo com Gil (2008, p. 28), a pesquisa descritiva "têm como objetivo primordial a descrição das características de determinada população ou fenômeno ou o estabelecimento de relações entre variáveis", permitindo uma visão mais ampla em relação a realidade da temática abordada na pesquisa, no qual descrevemos e analisamos com maior propriedade as opiniões de 
uma gestora, um docente e uma mãe de criança com deficiência em relação a atuação de professores homens com alunos especiais.

O instrumento de coleta de dados utilizado, para realização da pesquisa, foi a entrevista semiestruturada, na qual foi realizada por intermédio de ferramentas digitais, tais quais como o celular, sendo utilizado o aplicativo Whatsaap para gravar as entrevistas à distância. A intenção era gravar as entrevistas pessoalmente, mas, devido ao atual contexto de pandemia causado pelo Covid19, no qual as pessoas têm buscado se manter em isolamento social, como forma de combater esta nova doença, tornou-se necessário encontrar outras possibilidades, que no caso deste estudo teve resultado positivo.

Ao comentar sobre a entrevista como forma de realização de pesquisa qualitativa, Triviños (1987) menciona que a entrevista semiestruturada permite uma maior liberdade ao pesquisador, uma vez que a mesma se constitui por perguntas pré-elaboradas, no qual o pesquisador, se sentir necessidade, pode perguntar algo a mais do que está no roteiro de perguntas, tornando a entrevista mais flexível. Portanto, de acordo com o autor:

\footnotetext{
Podemos entender por entrevista semi-estruturada, em geral, aquela que parte de certos questionamentos básicos, apoiados em teorias e hipóteses, que interessam à pesquisa, $\mathrm{e}$ que, em seguida, oferecem amplo campo de interrogativas, fruto de novas hipóteses que vão surgindo à medida que se recebem as respostas do informante. Desta maneira, o informante, seguindo espontaneamente a linha de seu pensamento e de suas experiências dentro do foco principal colocado pelo investigador, começa a participar na elaboração do conteúdo da pesquisa (TRIVIÑOS, 1987, p. 146).
}

A pesquisa de campo foi realizada com uma gestora e um professor homem que trabalhavam na APAE de um município do interior de Mato Grosso do Sul e também com uma mãe de criança com deficiência que frequentava a APAE de outro município sul-mato-grossense. A fim de preservar a identidade dos três participantes da pesquisa, seus nomes foram omitidos e o perfil de cada um deles é:

1- Professor Homem que trabalha na APAE (Professor H): tem 30 anos de idade, é casado, não possui filhos, é formado em Educação Física, possui dois cursos de Especialização, sendo um na área de Educação Especial e Inclusiva, atua há quatro anos e meio na APAE e atualmente com turmas de crianças de 6 a 8 anos, que correspondem aos níveis de $1^{\circ}$ ao $3^{\circ}$ ano do Ensino Fundamental da APAE.

2- Gestora da APAE (Gestora): tem 50 anos de idade, é casada, não possui filhos, é licenciada em Pedagogia com três cursos de Especialização, sendo uma na área de Educação Especial e Inclusiva, trabalha há 8 anos trabalha na Área da Educação Especial, sendo 3 anos como professora de sala de Atendimento Educacional Especializado (AEE) e 5 anos como gestora da APAE. 
3- Membro familiar da APAE - mãe de menina (Mãe): tem 35 anos de idade, é casada e mãe de dois filhos, sendo um menino de 9 anos (sem deficiência) e uma menina de 2 anos que possui a Síndrome de Arnold Chiari tipo II (complicações com hidrocefalia e limitações motoras), a criança frequentou a turma do Maternal I da APAE, que corresponde ao berçário na Educação Infantil e tinha um professor homem nessa turma, a mãe possui formação técnica em Música (5 anos) e frequenta o último ano do curso de Pedagogia.

Os dados obtidos com a gravação das entrevistas, foram transcritos, sistematizados e analisados, constituindo assim os resultados e discussões que são apresentados na sequência.

\section{RESULTADOS E DISCUSSÕES}

Os resultados obtidos pela coleta de dados remetem a um contexto semelhante ao da Educação Infantil, evidenciando o binômio do cuidar e educar na instituição APAE, no qual os professores são preparados com cursos sobre cuidado e saúde, cuidado e segurança, além de cursos de os procedimentos pedagógicos, voltados a Educação Especial. Todavia, todo este cuidado costuma ficar mais restrito, quando o professor homem passa a realizar atividades voltadas ao cuidado e práticas higienistas com as crianças especiais, revelando um temor, por parte das mães e da própria instituição, em relação a atuação de professores homens na educação especial.

Isso ocorre porque as mães costumam ter um olhar assistencialista perante a educação ofertada pela APAE, tendo em vista que a instituição lida com crianças especiais que, de acordo com sua deficiência, demandam certamente de um cuidado ou atenção maior. Dessa forma, as mães ainda enxergam a educação especial pautadas em argumentos do determinismo biológico, para justificar que esta modalidade de ensino deveria ser voltada para professoras mulheres, devido estas serem dotadas de natureza maternal, passiva, compreensiva e cuidadosa, ao contrário do homem que tende a ser visto como rude, grosseiro e autoritário, tornando o espaço educacional apto para as mulheres (GONÇALVES; FERREIRA; CAPRISTO, 2018). Sendo assim, há uma grande generalização e naturalização das características que são impostas culturalmente pela sociedade sobre o que é masculino e feminino, baseado no fator biológico do indivíduo.

É devido a este receio que as mães possuem em relação a atuação do docente masculino em atividades voltadas para o cuidado pessoal das crianças especiais, a instituição adota meios para atender as demandas destas, no qual os professores homens devem evitar o máximo de realizar atividades voltadas ao cuidado pessoal. Tal postura contribui para reforçar o estereótipo de que apenas a mulher pode e deve realizar tais atividades, sendo um dos fatores que dificultam a superação de tabus em relação ao abuso sexual e pedofilia na Educação, que frequentemente são 
remetidos aos professores homens, como se estes não fossem capaz de controlar seus desejos sexuais e a mulher fosse isenta de sexualidade (GONÇALVES; FERREIRA; CAPRISTO, 2018). Diante deste cenário, o Professor $\mathrm{H}$, ao afirmar que optou por atuar na Educação Especial por dois motivos, esclarece que:

Desde pequeno tinha um olhar bem diferente para essas crianças, porque eu tinha uma prima com Hidrocefalia [...] A ida pra APAE foi porque estavam fechando turmas na JGP, eu precisava ir para outra escola e tinha uma escola regular e tinha a oportunidade de ir para APAE, aí entre a escola regular e a APAE por desafio profissional e por ter um olhar diferente lembrar da minha prima, etc. Eu escolhi ir pra APAE, mais por uma questão de é... não sei, de afeto... (PROFESSOR H).

Sendo assim, é perceptível que o professor escolheu a área da Educação Especial, devido ao fato de precisar mudar de escola e também da recordação afetiva de sua prima que foi um fato marcante na sua vida e um fator decisivo na sua escolha profissional, no qual acaba mencionando que sua decisão foi por uma questão de afeto. De acordo com Aguiar (2006), a escolha da profissão não é apenas uma decisão individual do indivíduo, mas acarretada de diversos fatores externos, no qual o sujeito sofre influência das experiências de mundo que possui, mas também da sua cultura, crenças, contexto histórico, condição social, da sua base familiar e escolar, de fatores emocionais, fatores políticos que presenciou, o prestigio da profissão, ofertar no mercado de trabalho, boa remuneração, entre outros aspectos.

Durante sua trajetória na Educação Especial, o mesmo relatou não sofrer preconceitos de seus amigos e familiares por sua escolha de atuar na Educação Especial, declarando que: "eu não recebi nenhuma crítica não, pelo contrário o pessoal falou olha é um desafio e tanto, você vai ter que estudar muito, é muito trabalhoso, mas é incrível, então assim eu recebi muito apoio" (PROFESSOR H). O mesmo posicionamento foi obtido tanto pelo Professor $\mathrm{H}$, quanto pela Gestora, quando foram questionados sobre a aceitação das famílias e da comunidade escolar em relação a sua atuação pedagógica do professor homem com as crianças especiais, no qual a Gestora relata: "A receptividade pelas famílias é tranquila, é muito boa, com os alunos maiores também sem nenhum problema, com os funcionários também nós não temos problemas em ter o professor do sexo masculino trabalhando entre a gente". O Professor $\mathrm{H}$ declara: "Na verdade eu fui bem aceito pelos pais, é eu não sei se, porque lá tinham muitos professores de muito tempo e..., quando eu cheguei chegaram outros professores, então deu uma modificada, acho que deu uma dinamizada um pouco nos trabalhos" e acrescenta:

Nunca tive problemas nenhum assim com a família, os funcionários, ninguém, é mais com a gestão mesmo que a gente tem uns embates sobre como trabalhar, as formas de trabalho, os materiais escassos né, o uso do dinheiro, mas fora isso ham... nunca tive nenhum problema sempre fui muito bem aceito, é a gente 
trabalha muito na colaboração ali com os colegas e outros funcionários, quando alguém precisa a gente tá sempre à disposição, então acho que foi bem tranquilo (PROFESSOR H).

Diante desta perspectiva, podemos notar a confirmação da Gestora em relação a receptividade positiva da família e da comunidade escolar com professor homem, no qual o Professor $\mathrm{H}$ relata que foi bem aceito tanto por seu núcleo familiar, quanto pela comunidade escolar e as famílias de seus alunos, no qual o professor também diz que apresenta alguns conflitos com a gestão escolar em relação as práticas pedagógicas, falta de recursos, entre outros fatores. Todavia, apesar do mesmo relatar que foi bem recebido pelos pais e pela comunidade escolar, este ainda apresentava certo receio em exercer atividades voltadas ao cuidado, declarando: "eu só fiquei esperto nesta questão mesmo dos cuidados pessoais, porque é... os professores mais antigos já tinham falado que era pra evitar e tomar muito cuidado, porque já tinha tido problema na instituição antes com outros professores" (PROFESSOR H).

Neste sentido, o professor relata que seus colegas de trabalho já haviam avisado para evitar realizar atividades voltadas ao cuidado e práticas higienistas, no qual o mesmo seguiu o conselho para evitar um futuro problema com os familiares, o que de certa forma, acaba contribuindo para a reprodução do estereótipo de que apenas mulheres conseguem e podem realizar atividades voltadas ao cuidado pessoal e higiene das crianças. Contudo, Sayão (2005, p. 261) relata que a instituição adota medidas para evitar possíveis conflitos com a família, no qual os professores homens ficam sujeitos a segui-las, pois “[...] o corpo masculino considerado sexualmente ativo deve ser privado de contatos mais próximos com as crianças. Poucos profissionais conseguem ultrapassar tais dificuldades. Muitos preferem aderir à cultura institucional". Seguindo esta perspectiva, a Mãe relata que ao descobrir que o professor sua filha era homem causou certo "estranhamento". Assim ela declara:

Então, nas primeiras semanas é, devido ao meu trabalho, não foi eu que tive contato com o professor lá, [...] meu marido que levava e até então ele não comentou nada comigo né, e... pra falar bem a verdade quando eu cheguei um dia e deixei minha filha com o professor, eu achei um pouquinho estranho (MÃE).

Neste trecho fica perceptível que o marido pareceu indiferente ao fato de o educador ser um homem, mas a Mãe apresentou um certo desconforto ao ver um professor homem lecionando com crianças especiais. Este fator de estranheza também foi constatado nas pesquisas de Sayão (2005) e Gonçalves, Faria (2015), pois tudo o que não nos é comum, ou que não atenda os padrões heteronormativos, produzidos socialmente e historicamente, é considerado como estranho. Dessa forma, Sá (1995, p 37) consolida que “[...] o estranho atrai, intriga e perturba as pessoas e as 
comunidades, provocando nelas o medo da perda dos referenciais habituais, do senso da comunidade e de compreensão mútua".

No entanto, apesar do estranhamento inicial, a mesma relata que todo este receio foi superado pela segurança e profissionalismo que o professor homem passou a ela, também disse o curso de pedagogia foi imprescindível para construir uma nova perspectiva em relação ao trabalho exercido pelo educador homem, no qual a mesma declara que seu pensamento mudou muito. Ela acredita que se fosse em tempos antigos, que sua filha tivesse um professor homem, que ela tiraria da instituição, mas a formação universitária contribuiu para a mudança de mentalidade. Para Buron (2016), a Universidade abre novos horizontes, novas perspectivas de se enxergar o que se parecia estranho em um primeiro momento, nos levando a sair do senso comum e pensar criticamente sobre as coisas, para que assim possamos desmitificar os mitos e credos limitantes da nossa cultura, para promover a transformação social. Por conseguinte, Sayão (2015) acrescenta que no início é normal os pais apresentarem certa resistência, contudo, no decorrer do tempo o processo de aceitação vai ocorrendo, no qual o reconhecimento profissional do professor homem é tratado como "diferente", de modo que o professor específico é reconhecido, mas o seu mérito não se perpassa para os demais, pois cada docente masculino deve passar pelo processo de aceitação individualmente, o denominado período comprobatório (RAMOS, 2011). Tendo isso em vista, a mãe argumenta que:

$[\ldots]$ nas outras semanas que eu fui perdendo aquele receio, porque assim [...] eu percebi que ele tinha um jeito é... pra criança e um amor muito grande com a minha bebê e com aquelas crianças né, que ali todas eram especiais, [...] ele foi muito muito atencioso com a minha filha e na verdade ele desmistificou, com as atitudes dele, tudo o que eu tinha assim de receio né, com a figura dele, de um homem com a minha uma menina. [...] antes, eu falo para você, que eu tinha muitas escamas nos olhos, então eu tinha muitas superstições, tradições, essas coisas [...] eu antes de cursar a faculdade, eu não deixaria minha filha né, eu penso olhando para trás como eu pensava com os olhos cheios de escama, porque para mim ia ser uma barreira muito grande, pode ser que eu até tiraria ela da escola. Mas falando hoje né, como eu falo para todo mundo que a minha filha é muito especial e a Pedagogia fez uma junção na minha vida com a dela, porque ela me abriu os olhos e me tirou as escamas né, e me deu outras perspectivas de vida né, pensando na minha filha e nas outras crianças também (MÃE).

No caso da Gestora, com base em sua experiência na Educação Especial, tendo em vista que lecionou 3 anos como professora da sala de Atendimento Educacional Especializado o AEE e 5 anos como Diretora da instituição APAE, ela menciona que, de acordo com a sua percepção a resistência das famílias com o professor homem era maior na Educação Infantil do que na Educação Especial, declarando: "Então, eu como trabalhei no município também, na área de Educação Infantil em creche, eu achei assim a resistência dos pais muito grande, agora quando eu vim aqui para a APAE e já tinha alguns professores, tinham mais na época que eu entrei”. O que 
de certa forma acaba evidenciando as resistências da família relatadas anteriormente pelo Professor H e pela Mãe, no qual mesmo sendo de forma reduzida, segundo a Gestora, ainda sim a família possui receio quanto a atuação do professor homem com crianças especiais.

Essa receptividade maior na Educação Especial é justificada tanto pela Gestora quanto pelo Professor $\mathrm{H}$, pelo fato de já haver professores homens atuando na instituição, antes mesmo de ambos estarem exercendo seu trabalho na instituição APAE, como pode-se notar na fala do Professor H: "Não, na verdade eu fui bem aceito pelos pais, é eu não sei se porque lá tinham muitos professores de muito tempo e... quando eu cheguei chegaram outros professores”. Sendo assim, podemos perceber que devido a comunidade escolar e as famílias já estarem "acostumadas" com a presença masculina nas salas de aulas da instituição, pode ser que tenham naturalizado a presença masculina na instituição APAE.

Em relação as atividades voltadas para o cuidado pessoal e práticas higienistas, os participantes comentam sobre as relações de gênero predominantes, visto que as mulheres, geralmente, são vistas como mais adequadas para desenvolver essas funções, como pode ser observado nos seguintes relatos:

Até o ano passado, nós tínhamos uma pessoa responsável né, para trocar a fralda para fazer a higienização tá [...] esse ano que nós não temos ainda essa pessoa para auxiliar na troca né de fraldas. Em relação as meninas né, que são adolescentes, pré-adolescentes, adolescentes que ficam no seu período de regras [menstruação], as famílias são orientadas a não mandar na escola... a não mandar na escola, porquê? Por causa da troca do absorvente que é assim mais delicado [...] quem realiza essa função é uma mulher (GESTORA).

$\mathrm{Na}$ APAE tem a... o pessoal que, faz a parte da higiene pessoal das crianças, então se precisar trocar frauda, tem o pessoal que troca a fralda das crianças, o máximo que a gente faz, na questão do cuidado pessoal da criança, é na hora da alimentação, a gente dá comida para as crianças que não conseguem comer sozinhas. $\mathrm{Na}$ verdade, são... são mulheres, as meninas do corredor que a gente tem lá, que são da limpeza e fazem essa função, antes tinha monitor, mas as monitoras foram demitidas e eles usam o pessoal da limpeza. Não há uma restrição clara sobre isso, o que acontece é que existe um cuidado para evitar problemas com as mães, que as mães circulam muito pela instituição, então a gente evita que elas tenham um entendimento errado de alguma circunstância. Por exemplo, um professor homem acompanhando uma criança no banheiro é uma coisa que gera muita contradição com as mães, porque já teve essas situações antes e as mães, elas não gostam, então a gente evita problemas com as mães né, a instituição é uma associação de pais, então os pais, eles são os donos da instituição, não... A direção então ela toma muito cuidado, não existe uma clara restrição, mesmo porque numa situação de emergência a gente vai, né, um aluno que está com ânsia de vomito muito forte a gente vai com ele ao banheiro se der tempo, mas a gente evita ao máximo né, principalmente professor homem. (PROFESSOR H).

Então, eu sempre..., para falar a verdade, me parece que nunca deu me deu essa estranheza depois que eu acabei aceitando a situação né, e [...] respeitando muito 
o professor e o trabalho dele, e... como que eu que eu sempre via, eu via ele muito profissional, muito carinhoso e muito cuidadoso. Então assim, ali para a minha filha, ele era uma figura paterna né, então eu penso assim, o meu marido, ele troca fraldas da minha filha em casa né, e lá o professor, ele também tem, como ele está na Educação Infantil [...] eu fiquei assim, procurei sempre imaginar que ele sempre foi um professor cuidadoso, profissional, que ele estava ali pra cuidar da minha filha e que não tinha nada demais dele trocar uma fralda dela ou dar um banho nela (MÃE).

Com base nessas percepções, pode-se notar na fala do professor, resultados semelhantes aos estudos das pesquisadoras Gonçalves e Faria (2015), Gonçalves, Ferreira e Capristo (2018) que apontaram em suas pesquisas que o professor homem é privado de realizar atividades voltadas ao cuidado pessoal e práticas higienistas, no qual sempre há uma mulher para realizar tal função. Isto ocorre devido a visão assistencialista atribuída pelos pais e pela própria instituição em relação as práticas pedagógicas com crianças especiais, nessa perspectiva o cuidar acaba de certa forma se sobrepondo em relação ao educar, tendo em vista que estas crianças possuem condições específicas que demandam um cuidado e atenção maior dos professores, o que nos faz remeter ao estereótipo de que a mulher por possuir sua natureza maternal, está mais apta a cuidar destas crianças, mesmo que a mesma não possua formação para realizar tal prática. Na própria fala da mãe, apesar de aceitar a situação e de ressignificar a atuação profissional do professor homem com um ato comum do seu cotidiano exercido por seu marido, ainda apresenta uma visão muito mais assistencialista do que educativa (MONTENEGRO, 2005).

É evidente que os professores homens se sujeitam as normas da instituição, para evitar possíveis confrontos com a família, devido ao corpo masculino ser socialmente e culturalmente construído como sexualmente ativo, o que causa certa repulsa aos pais de ver um homem trabalhando com crianças que possuem deficiências que necessitam de uma atenção especial, associando o mesmo a pedofilia e ao abuso sexual. Isso fica evidente quando a mãe cita os receios dos pais em relação a prática docente, relatando: "Eu falo com toda certeza, pelo que eu já ouvi e pelo que eu já vivi né, também, é a questão unicamente que eu falo para você, é a questão da troca né, essa questão de banho, que eles acham que o homem não, não faz isso, não é pra fazer isso" (MÃE).

Deste modo, há uma naturalização das práticas que devem ser exercidas por homens e mulheres pautados no determinismo biológico, no qual tudo que foge ao padrão pré-estabelecido socialmente é visto como estranho, inadequado ou incomum (SAYÃO, 2015; HIRATA; KERGOAT, 2007). Sendo assim, a Gestora nota que a família tem mais segurança quando a mulher realiza as atividades voltada ao cuidado pessoal, mencionando: "Então é... nesse sentido, eu né, observei que as famílias se sentem mais seguras em se tratando de uma pessoa do sexo feminino, para fazer essas trocas de fraldas, elas se sentem mais seguras". 
Quando questionados sobre a preferência de escolher uma turma sob o comando de um professor homem e outra sob o comando de uma professora mulher, o Professor $\mathrm{H}$ relatou que por estar atuando na área de Educação Física não percebe nada que impossibilite os pais de deixarem seus alunos com o mesmo. Todavia, diz que em relação aos docentes masculinos que atuam como regentes principais da sala de aula percebe uma estranheza por parte dos pais, declarando: "A educação está muito com uma educação associada ao cuidado da Educação Especial e ao cuidado assistencialista e maternal, talvez cause alguma estranheza né a mãe olhar o professor homem, mas no ponto de vista da educação física não" (PROFESSOR H).

A Mãe relata que tinha dificuldade de responder este tópico, pois a disse que caso se deparasse com um professor que a passasse segurança não hesitaria em escolhê-lo, mas caso contrário, declara: "Eu só deixaria minha filha com um professor do sexo masculino se ele me passasse o que aquele professor passou pra mim, segurança né, muito amor e carinho e cuidado com a minha filha”. E acrescenta: "Ao contrário eu preferia deixar com uma professora, porque a mulher como nós todos sabemos e a sociedade pregou isso que ela é uma figura materna" (MÃE). A Gestora possui uma perspectiva diferente da mãe, relatando que os pais são muito receptíveis e que não teve nenhum problema em relação a uma família querer trocar de sala pelo gênero do professor, declarando: “a família não tem nenhum problema, [...] no quesito é... por sexo masculino ou feminino, por enquanto... por enquanto, não tive assim nenhum problema, não estou tendo nenhum problema em relação a... ao sexo".

Com isso, percebe-se novamente a questão da visão assistencialista presente na instituição, que é vista pelas mães como instituições que promovem mais o cuidar do que o educar, o que gera certo estranhamento nos familiares, ao ver um homem atuando em uma área considerada feminina pela sociedade. Isso corre porque há o predomínio do determinismo biológico para justificar que a área da educação especial infantil deve ser composta por mulheres, por conta do estereótipo criado culturalmente no qual as mulheres são consideradas cuidadosas, educadoras natas, carinhosas e dotadas de natureza maternal. Tal postura acaba, de certa forma, delimitando as profissões numa perspectiva sexista, atribuindo que a prática educativa como algo próprio e natural da mulher, o que certamente acaba segregando as possibilidades de homens e mulheres exercerem profissões, prevalecendo a ideia de que toda profissão que é voltada para o âmbito doméstico é caraterizada como feminina, e toda a profissão voltada para a esfera produtiva é considerada masculina (SAYÃO, 2015; HIRATA; KERGOAT, 2007).

Quando questionados sobre a pouca quantidade de professores homens atuando na Educação Especial com crianças especiais, o Professor $\mathrm{H}$ relata que "Na Educação Física a gente percebe que esse excesso de cuidado maternal não está presente". Entretanto, o professor 
acrescenta: "mas eu creio que é por isso, uma visão muito maternal ainda, muito assistencialista sobre a educação especial". A Mãe fala que os professores homens devem enfrentar muitas barreiras na instituição de Educação Especial, sendo estas uma das principais resistências dos pais referente a atuação de professores homens em relação as atividades voltadas ao cuidado pessoal e práticas higienistas. Ela ressalta o grande temor dos pais, que associam a figura masculina ao abuso sexual e a pedofilia, declarando:

As vezes a gente pensa que o homem não tem esse instinto com ele também, de trocar fralda de dar banho, eu penso que assim... e também na questão de quando se trata de uma criança especial a gente acha que eles não vão ter capacidade de cuidar dos nossos filhos como nós [...] As mães sempre falam "Como que eu vou deixar um professor trocar minha filha, limpar minha filha, dar banho na minha filha...", sempre vai mais para esse lado [...] É que elas têm dificuldade de enxergar, no professor, um profissional (MÃE)

A Gestora relata que a falta de professores homens na Educação Especial é pela pouca procura destes em realizar graduação de licenciatura, dizendo também que os homens tendem a ter receio e não saber como lidar com crianças especiais, ressaltando que os mesmos possuem uma visão mais assistencialista da instituição APAE. Desta forma, é perceptível que a Gestora menciona vários estereótipos para tentar justificar a pouca quantidade de docente docentes homens na Educação Especial, no entanto, a mesma ressalta a importância do educar na instituição, declarando:

[...] é muito importante, a... o aumento da procura de... do professor, dos professores homens né, na graduação de licenciatura né, apesar que de uns tempos para cá eu estou vendo muito, muito pouca procura né, ainda, o que que acontece em relação a Educação Especial [...] não tem um conhecimento de como é realizado o trabalho de um aluno com deficiência dentro de uma escola especial né. Eu acho assim, que eles vão ficar com dó, que não sabe como vai lidar, que os alunos né, que estão inseridos na escola especial, são uns coitadinhos, incapazes né, que eles vão ter que fazer o papel... o papel de cuidar e não é isso, não é o papel de cuidar e sim do aprender. [...] foi o tempo em que trabalhava-se somente o assistencialismo, agora nós trabalhamos realmente o pedagógico.

Dessa forma, o Professor $\mathrm{H}$ complementa ao falar sobre o que falta para mais professores homens optarem pela profissão:

Talvez um pouco mais de segurança em trabalhar com crianças especiais né, só o fato de você falar para alguém que não tem estudo na área, não conhece, não se interessa pelo assunto, você falar ou propor, convidar pra trabalhar causa uma estranheza, uma repulsa inicial, não pelas crianças, mas pela situação de não saber trabalhar com o inesperado né. [...] além da visão né, deixar de achar que a Educação Especial, a Educação Infantil é coisa de mulher, porque mulher vira mãe, mulher cuida de criança, historicamente a mulher fica em casa, cuida das crianças e o homem sai para trabalhar mexe com coisas mais difíceis, mais 
pesadas, então o mais complexo da educação que seria o Fundamental II e o nível Médio fica para os homens. Já o mais fácil da educação, que não é fácil na verdade né, mas o mais delicado, vamos dizer, fica para a mulher. Isso é uma visão bem estereotipada, aí acho que tem que romper com isso, falta conhecimento, falta estudo, os professores talvez eles não se interessam, ah falta iniciativa mesmo deles.

Tendo isso em vista, é perceptível a dificuldade que as famílias e até mesmo a comunidade escolar possui de reconhecer o professor homem como profissional legitimado da instituição, uma vez que segundo Ramos (2011) o docente masculino passar por um período comprobatório como forma de provar suas capacidades no exercício da docência, para então ser reconhecido e "legitimado" como professor pela instituição, um período que as docentes do gênero feminino não passam, isso fica evidente na medida que a Mãe declara: "Eles enfrentam muitas reações negativas dos pais né, críticas até mesmo do corpo docente, a desconfiança da sociedade com a humanidade né, e eles se sentem na obrigação de provar que têm capacidade e as suas verdadeiras intenções".

Contudo, as práticas sexistas nas divisões das profissões, ainda são precursoras dos estereótipos que designam o trabalho do homem e da mulher, o que acabam condicionando os indivíduos a pensarem e reproduzirem preconceitos quando se deparam com pessoas atuando em áreas que não correspondem ao padrão já esperado pela sociedade. Assim, surge a visão que o Professor H disse logo acima, de que a educação com crianças pequenas e especiais são coisas para mulher, evidenciando logicamente que as profissões voltadas para esfera domiciliar são consideradas naturalmente femininas (HIRATA; KERGOAT, 2007), contudo o mesmo declara:

[...] aí você entende que quando um professor fala que não vai trabalhar porque acha difícil, acha que mulher tem mais jeito, aí a gente se começa a se perguntar né, que jeito é esse que a mulher tem em trabalhar na Educação Especial, que o homem não tem né... é o jeito materno? Será que tem que ser mãe ou tem que ter um organismo próprio para ser mãe para se trabalhar na Educação Especial? Isso daí ainda é um estereótipo muito antigo, então eu acho que é importante as pessoas tentarem, especializarem, estudarem para trabalhar na Educação Especial, mais pela questão de desmistificação de certos estigmas que a gente carrega, que a nossa sociedade carrega (PROFESSOR H).

Para finalizar a análise dos resultados, destaca-se uma frase que foi dita pela Mãe: "Desejo que algum dia que a nossa sociedade tenha uma nova conduta, então o início de uma nova conduta né, com a igualdade dos seus profissionais como sujeitos que promovem a educação independente do sexo que possuem". Todavia, ouse dizer que desejo que isto se perpasse para todas as profissões, para que haja a superação das relações limitantes de gênero e das práticas sexistas na determinação de profissões de homens e mulheres. 


\section{CONSIDERAÇÕES FINAIS}

Ao voltarmos o olhar para o objetivo da pesquisa, de identificar as percepções de docentes masculinos, familiares e gestores da área de educação especial sul-mato-grossense, para compreender as representações sociais e estereótipos atribuídos ao professor homem que atua com crianças especiais na APAE, nota-se uma grande semelhança com os resultados apontados pelas pesquisas referentes à docência masculina na Educação Infantil. Apesar da boa receptividade familiar na Educação Especial, os professores homens ainda são privados de realizar atividades voltadas ao cuidado pessoal e as práticas higienistas, tendo em vista que a instituição adota estas medidas para evitar possíveis conflitos com a família, com o pretexto de que os pais se sentem mais seguros quando uma mulher realiza tais atividades. Tal postura acaba auxiliando no processo de reprodução de estereótipos de funções que são próprias do homem e própria da mulher.

É perceptível que a instituição em si e os pais apresentam uma visão assistencialista da APAE, uma vez que a família tem uma visão muito maternal da instituição, tendo em vista que as crianças especiais possuem suas especificidades e necessitam de uma atenção ou cuidado maior, o que acaba causando uma certa estranheza nas mães quando se deparam com professores homens atuando com crianças que possuem deficiências. Isso ocorre, pois, as famílias tendem a reproduzir um estereótipo muito antigo, mas que ainda perdura nas instituições de ensino voltadas as crianças, no qual tendem a acreditar que as mulheres têm "mais jeito", são mais cuidadosas, carinhosas, compreensivas por natureza, devido a sua natureza maternal. Consequentemente, surge a resistência em relação a presença masculina dentro da sala de aula, causando medo e receio nos pais do professor homem abusar das crianças, como se este não fosse capaz de controlar seus desejos sexuais, enquanto que a professora mulher é vista como assexuada. Tais percepções representam a grande dificuldade de se reconhecer o professor homem como profissional.

Deste modo, apesar de promover o educar e não somente o cuidar na instituição APAE, é notável que a instituição ainda possui em si, uma visão muito enraizada no assistencialismo, uma vez que priva os professores homens de exercer funções, se embasando na perspectiva dos pais, o que acarreta na reprodução dos estereótipos de papéis próprios do homem e da mulher. Esses estereótipos acabam contribuindo para dificultar o campo de trabalho na Educação Especial para os homens, uma vez que, muitos se sentem inseguros quanto as reações dos familiares, assim como os estereótipos voltados a profissão como se a educação com crianças devesse ser voltada apenas para mulheres, gerando um possível medo de rejeição. Surge então a importância de superar os estereótipos atribuídos as relações de gênero e práticas sexistas nas profissões, para que as pessoas 
possam ser, fazer e escolher o que querem independente das limitações causadas pelo determinismo biológico.

Contudo, enfatiza-se sobre a importância de se pesquisar mais acerca da temática e de forma mais especifica, com base nos olhares individuais de vários gestores, professores e familiares, para compreender mais profundamente as representações atribuídas ao professor homem na Educação Especial.

\section{REFERÊNCIAS}

AGUIAR, Wanda Maria Junqueira de. A escolha na orientação profissional: contribuições da psicologia sócio-histórica. Psicol. educ., São Paulo, n. 23, p. 11-25, dez. 2006. Disponível em $<$ http://pepsic.bvsalud.org/scielo.php?script=sci_arttext\&pid=S141469752006000200002\&lng=pt\&nrm=iso >. Acesso em: 18 jul. 2020.

BRASIL. Lei $\mathbf{n}^{\circ} . \mathbf{7 . 8 5 3}$, de 24 de Outubro de 1989. Dispõe sobre o apoio às pessoas portadoras de deficiência, sua integração social, sobre a Coordenadoria Nacional para Integração da Pessoa Portadora de Deficiência - Corde institui a tutela jurisdicional de interesses coletivos ou difusos dessas pessoas, disciplina a atuação do Ministério Público, define crimes, e dá outras providências. Brasília, 1989. Disponível em: <http://www.planalto.gov.br/ccivil_03/leis/L7853.htm>. Acesso em:

BRASIL. Ministério da Educação. Secretaria de Educação Especial. Diretrizes nacionais para a educação especial na educação básica. Brasília, 2001. Disponível em: < http://portal.mec.gov.br/seesp/arquivos/pdf/diretrizes.pdf $>$. Acesso em:

BOURDIEU, Pierre. A dominação Masculina. Tradução Maria Helena. 11 ed. Rio de Janeiro: Bertrand Brasil, 2012. Disponível em:

$<$ https://edisciplinas.usp.br/pluginfile.php/762315/mod_folder/content/0/BOURDIEU_A\%2 0domina \%C3\%A7\%C3\%A3o\%20masculina.pdf?forcedownload=1>. Acesso em: 10 ago. 2019.

BURON, Roberto Montagner. O papel da universidade na formação do perfil profissional. Salão do Conhecimento, v. 2, n. 2, 2016. Disponível em:

$<$ https://publicacoeseventos.unijui.edu.br/index.php/salaoconhecimento/article/view/7307>. Acesso em:

CRESWELL, John W. Projeto de pesquisa: métodos qualitativo, quantitativo e misto. Tradução de Luciana de Oliveira da Rocha. 2. ed. Porto Alegre: Artmed, 2007. Disponível em: $<$ https://edisciplinas.usp.br/pluginfile.php/696271/mod_resource/content/1/Creswell.pdf>. Acesso em: 15 ago. 2019.

GIL, Antonio Carlos. Métodos e técnicas de pesquisa social. 6. ed. São Paulo: Atlas, 2008. Disponível em: < https:// ayanrafael.files.wordpress.com/2011/08/gil-a-c-mc3a9todos-etc3a9cnicas-de-pesquisa-social.pdf >. Acesso em: 15 ago. 2019.

GONÇALVES, Josiane Peres; DIAS, Érica Fernanda Moreira; SOUZA, Valdelice Cruz da Silva. Eles são instáveis, agressivos e desnaturados ou têm autoridade, bom senso e firmeza? Presença de homens no magistério e representações sociais. Polêm!ca. Rio de Janeiro, v. 17, n. 4, p. 44-65, 
out./dez. 2017. Disponível em: <https://www.e-

publicacoes.uerj.br/index.php/polemica/article/view/34303/24293>. Acesso em: 15 ago. 2019.

GONÇALVES, Josiane Peres; FARIA, Adriana Horta. Representações sociais de famílias sobre a atuação de homens professores com crianças de educação infantil. Cadernos de Pesquisa em Educação. Vitória/ES, ano 12, v. 19, n. 41, 2015. Disponível em: < http://www.periodicos.ufes.br/educacao/article/view/11326>. Acesso em: 15 ago. 2019.

GONÇALVES, Josiane Peres; FERREIRA, Verônica Caroline de Matos; CAPRISTO, Zenaide Ribeiro Neto. Professores homens desempenham as mesmas funções que as professoras na Educação Infantil? Olhares dos gestores escolares. Educação em Foco, v. 21, n. 34, p. 125-145, 2018. Disponível em: <http://revista.uemg.br/index.php/educacaoemfoco/article/view/1470>. Acesso em: 15 ago. 2019.

GUEDES, $M^{a}$ Eunice Figueiredo. Gênero, o que é isso? Psicol. cienc. prof., Brasília, v.15, n. 1 3, p. 4-11, 1995. Disponível em:

$<$ http:/ / www.scielo.br/scielo.php?script=sci_arttext\&pid=S1414-

98931995000100002\&lng=en\&nrm=iso >. Acesso em: 16 ago. 2019.

HIRATA, Helena; KERGOAT, Danièle. Novas configurações da divisão sexual do trabalho. Cad. Pesqui. São Paulo, v. 37, n. 132, p. 595-609, Dez. 2007 . Disponível em:

$<$ http://www.scielo.br/scielo.php?script=sci_arttext\&pid=S0100-

$15742007000300005 \& \operatorname{lng}=$ en\&nrm=iso $>$. Acesso em: 08 set. 2019.

MONTENEGRO, T. Educação Infantil: a dimensão moral da função de cuidar. Psicologia da Educação, São Paulo, v. 20, p. 77-101, 2005.

RAMOS, Joaquim. Um estudo sobre os professores homens da Educação Infantil e as relações de gênero na rede municipal de Belo Horizonte-MG. Pontifícia Universidade Católica de Minas Gerais, Programa de Pós-Graduação em Educação Belo Horizonte, 2011.

Disponível em: < http://www.biblioteca.pucminas.br/teses/Educacao_RamosJ_1.pdf>. Acesso em: 23 ago. 2019.

SÁ, C. P. Representações Sociais: o conceito e o estado atual da teoria. In: SPINK, M. J. (org.). O conhecimento no cotidiano. São Paulo: Brasiliense, 1995.

SAYÃO, Deborah Thomé. Relações de gênero e trabalho docente na educação infantil: um estudo de professores em creches. 2005. 273 f. Tese (Doutorado) - Universidade Federal de Santa Catarina, Centro de Ciências da Educação, Florianópolis. Disponível em: <https://repositorio.ufsc.br/bitstream/handle/123456789/106572/223081.pdf?sequence=1\&is Allowed $=\mathrm{y}>$. Acesso em: 15 ago. 2019.

TRIVIÑOS, Augusto Nibaldo Silva. Introdução à pesquisa em ciências sociais: a pesquisa qualitativa em educação. São Paulo: Atlas, 1987. Disponível em: $<$ https://edisciplinas.usp.br/pluginfile.php/4233509/mod_resource/content/0/TrivinosIntroducao-Pesquisa-em_Ciencias-Sociais.pdf>. Acesso em: 15 ago. 2019. 